\title{
Serapilheira e nutrientes acumulados sobre o solo em plantios de leguminosas e em área restaurada com espécies nativas da Floresta Atlântica
}

\author{
Marcos Vinicius Winckler Caldeira ${ }^{1}$, Huezer Viganô Sperandio $\oplus^{2}$, Tiago de Oliveira Godinho $\circledast^{3 *}$, \\ Valéria Hollunder Klippel ${ }^{1}$, William Macedo Delarmelina $\oplus^{4}$, Elzimar de Oliveira Gonçalves ${ }^{1}$, \\ Paulo André Trazzi@1
}

${ }^{1}$ Universidade Federal do Espírito Santo, Av. Gov. Lindenberg, 316, Centro, CEP 29.550-000, Jerônimo Monteiro, ES, Brasil

${ }^{2}$ Universidade Federal dos Vales do Jequitinhonha e Mucuri, Rodovia MGT 367, Km 583, 5.000, Alto da Jacuba, CEP 39.100-000, Diamantina, MG, Brasil

${ }^{3}$ Vale S/A - Reserva Natural Vale, BR 101, KM 122, Farias, CEP 29.911-080, Linhares, ES, Brasil

${ }^{4}$ Instituto Federal do Espírito Santo, Av. 7 de Novembro, 40, Campus Ibatiba, CEP 29.395-000, Ibatiba, ES, Brasil

\section{Original Article \\ *Corresponding author: godinhoto@hotmail.com \\ Palavras-chave: \\ Ciclagem biogeoquímica \\ Reserva Natural Vale \\ Recuperação de áreas degradadas \\ Keywords: \\ Biogeochemical cycling \\ Vale Natural Reserve \\ Recovery of degraded areas}

Received in

2019/05/02

Accepted on

2020/04/04

Published in

2020/06/30

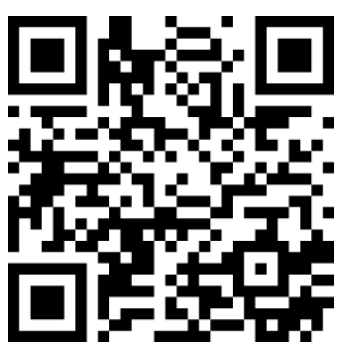

DOI:

https://doi.org/10.34062/afs. v7i2.8310

\section{(cc) BY}

RESUMO: Informações a respeito da sazonalidade, quantidade e qualidade da serapilheira acumulada fornecem subsídios para um melhor entendimento da dinâmica da ciclagem de nutrientes nos ecossistemas terrestres. Diante disso, este estudo objetivou quantificar a serapilheira acumulada e determinar o seu teor e conteúdo de nutrientes, em três diferentes coberturas vegetais na Reserva Natural Vale, Linhares - ES: área com a leguminosa (Fabaceae) subarbustiva Mimosa velloziana Mart., área com a leguminosa (Fabaceae) arbustiva Tephrosia candida DC. e área restaurada com espécies nativas da Floresta Atlântica, na estação chuvosa e na estação seca. Não foram observadas diferenças no acúmulo de serapilheira dentro da mesma cobertura vegetal, entre as estações climáticas. A área sob $M$. velloziana teve maior biomassa de serapilheira acumulada, seguida da área restaurada e da área com $T$. candida. A espécie $M$. velloziana proporcionou a serapilheira acumulada com maiores teores e conteúdos de macronutrientes, com exceção do cálcio, cujos teores e conteúdos foram maiores na serapilheira acumulada na área restaurada. As serapilheiras acumuladas das espécies leguminosas tiveram maiores teores e conteúdos de nitrogênio. O conteúdo total dos micronutrientes foi maior na serapilheira acumulada na restauração. A leguminosa $M$. velloziana se configurou como ótima opção para ser utilizada na recuperação de áreas degradadas e como espécie para compor sistemas agroflorestais, por retornar grande quantidade de nutrientes para o solo, por meio da serapilheira.

\section{Litter and nutrients accumulated on the ground in legumes plantations and in a restored area with native species from the Atlantic Forest}

\begin{abstract}
Information on respect for seasonality, quantity and quality of accumulated litter, subsidies for a better understanding of the dynamics of nutrient cycling in terrestrial ecosystems. Therefore, this study aimed to quantify the accumulated litter and determine its levels and nutrient contents, in three different vegetation coverings in the Vale Natural Reserve, Linhares - ES: area with the legume (Fabaceae) subshrub Mimosa velloziana Mart., area with the legume (Fabaceae) shrub Tephrosia candida DC. and a restored area with native species from the Atlantic Forest, in the rainy and dry seasons. There were no differences in litter accumulation within the same vegetation cover, between climatic seasons. The area under $M$. velloziana had the highest accumulated litter biomass, followed by the restored area and the area with $T$. candida. The M. velloziana species provided the accumulated litter with higher levels and contents of macronutrients, with the exception of calcium, whose levels and contents were higher in the litter accumulated in the restored area. The accumulated litter of leguminous species had higher levels and contents of nitrogen. The total micronutrient content was higher in the litter accumulated in the restoration. The legume M. velloziana was configured as an excellent option to be used in the recovery of degraded areas and as a species to compose agroforestry systems, as it returns a large amount of nutrients to the soil, through litter.
\end{abstract}




\section{Introdução}

O bioma Mata Atlântica abrange muitos tipos de ecossistemas tropicais e possui uma das maiores biodiversidades e endemismo do mundo (Myers et al. 2000; Ribeiro et al. 2009). Somados todos os fragmentos de floresta nativa acima de três ha, têmse atualmente $12,5 \%$ de remanescentes (SOS Mata Atlântica 2016). Após o abandono de áreas utilizadas para agricultura, pecuária ou plantios comerciais nesse bioma, a regeneração natural ocorre de maneira lenta e incerta, e varia de acordo com o tempo e a forma de uso anterior do solo, principalmente em virtude da perda de matéria orgânica, empobrecimento químico deste e dominância de gramíneas (Piña-Rodrigues et al. 1997). Esse quadro evidencia a importância de ações que minimizem a degradação e viabilizem a conservação e recuperação dessas áreas que foram altamente impactadas, principalmente por diferentes atividades antrópicas (Klippel et al. 2015; Correia et al. 2016).

A fim de recuperar áreas degradadas e facilitar o processo de regeneração florestal, devem ser plantadas espécies de rápido crescimento e que possibilitem melhorias na fertilidade do solo, por meio da deposição de material orgânico e ciclagem de nutrientes, promovendo um efeito catalítico no processo de recuperação (Caldeira et al. 2019). Nesse sentido, as espécies leguminosas (Fabaceae) apresentam papel de destaque para a inserção em ambientes com pouca ou nenhuma resiliência, devido à alta deposição de serapilheira e, principalmente, pela fixação biológica de nitrogênio atmosférico (Chaer et al. 2011; Longo et al. 2011). Estudos mostraram que a introdução de leguminosas em áreas de pastagem degradada melhora a qualidade química da serapilheira e aumenta o retorno de biomassa e nitrogênio para o solo (Freitas et al. 2013; Silva et al. 2013), consequentemente aumentando a taxa de decomposição do material (Gomes Júnior et al. 2019).

Um fator preponderante na avaliação da serapilheira acumulada, além de sua biomassa, é o teor dos nutrientes que a constitui, pois, a serapilheira é responsável pela retenção de grandes quantidades de nutrientes. A serapilheira é a via mais importante de retorno dos nutrientes absorvidos pelas plantas para o solo (Godinho et al. 2013), especialmente nas florestas tropicais situadas em solos com baixa fertilidade natural (Godinho et al. 2014). Portanto, a serapilheira é considerada um indicador de avaliação e monitoramento de projetos de restauração florestal (Sperandio et al. 2012; Costa et al. 2014; Siqueira et al. 2014; Nascimento et al. 2015; Correia et al. 2016; Klippel et al. 2016; Caldeira et al. 2019).

A Mimosa velloziana Mart. caracteriza-se por ser uma espécie reptante, que atinge aproximadamente um metro de altura, já a Tephrosia candida DC. é uma espécie arbustiva, que atinge aproximadamente $2,5 \mathrm{~m}$ em altura, possuindo então, formação arquitetônica distintas entre si. As espécies supracitadas possuem potencial para inserção em projetos de recuperação de áreas degradas e para adubação verde, pois produzem grande quantidade de biomassa com altos teores de nutrientes (Caldeira et al. 2014).

Alguns autores acreditam que as espécies de leguminosa subarbustiva Mimosa velloziana Mart. e arbustiva Tephrosia candida DC. possuem potencial para uso em projetos de recuperação de áreas degradadas. Contudo, ainda não existem relatos de estudos direcionados à contribuição de tais espécies sob aspectos da ciclagem de nutrientes. Diante do exposto, o estudo objetivou avaliar a sazonalidade, quantidade e qualidade química (teor e conteúdo de nutrientes) da serapilheira acumulada em áreas com as referidas espécies leguminosas, e uma área de restauração florestal.

\section{Materiais e métodos}

A área de estudo se localiza na Reserva Natural Vale (RNV), sob as coordenadas geográficas $19^{\circ} 08^{\prime} 40^{\prime \prime} \mathrm{S}$ e $40^{\circ} 04^{\prime} 08^{\prime \prime} \mathrm{W}$, no município de Linhares, estado do Espírito Santo. A RNV possui cerca de 23 mil ha de Floresta Atlântica, sobre terrenos com pequena variação de altitude, geralmente entre 30 e $60 \mathrm{~m}$ acima do nível do mar. Saiter et al. (2017), sugerem classificar a floresta nativa da RNV duplamente como estacional semidecidual nos períodos anuais ou supra-anuais caracterizados por déficit hídrico pronunciado, e como floresta estacional perenifólia nos períodos anuais ou supra-anuais sem déficit hídrico significativo.

De acordo com a classificação de Köppen, o clima da região é do tipo Aw, tropical quente e úmido, com estação chuvosa no verão e seca no inverno (Alvares et al. 2013). A média das temperaturas mínimas e máximas do ar são de $18,7^{\circ} \mathrm{C}$ e $29,9^{\circ} \mathrm{C}$, respectivamente. A precipitação média anual é de 1.214,6 mm (Saiter et al. 2017). O solo é classificado como Argissolo Amarelo Distrocoeso (EMBRAPA 2006).

As espécies leguminosas estão localizadas em uma área denominada "Banco de Leguminosas", que consiste em monocultivos de 10 diferentes espécies de leguminosas, com 0,5 ha de cada espécie. Para o presente estudo, foram delimitadas três áreas, cada uma com 0,5 ha: área composta por T. candida, área composta por M. velloziana e área composta por restauração florestal, que se encontrava ao lado do banco de leguminosas (Figura $1)$. 


\section{Caldeira et al.}

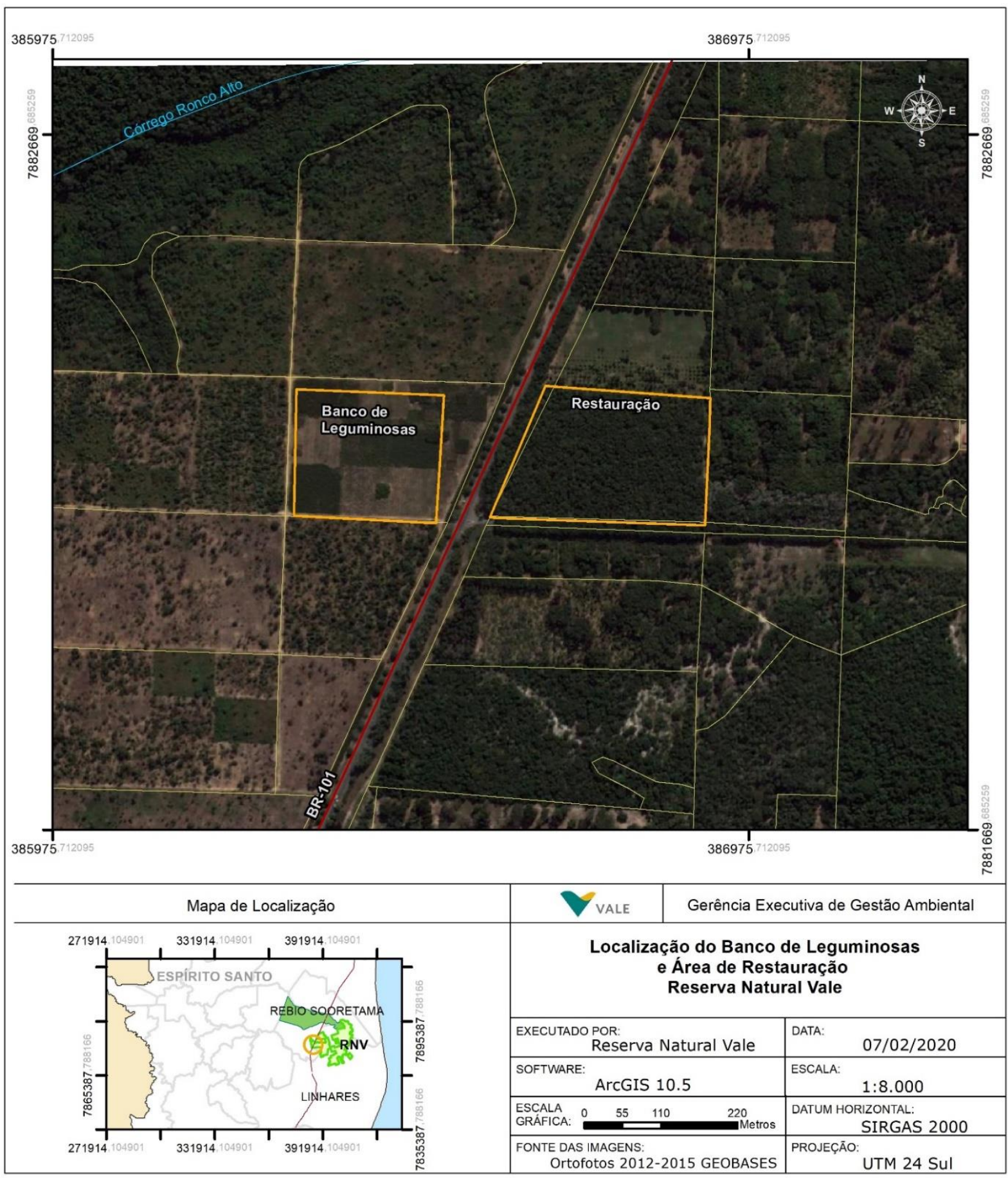

Figura 1. Mapa de localização da área experimental na Reserva Natural Vale, Linhares, ES.

Antes do plantio das espécies leguminosas em outubro de 2008, na década de 80 as áreas eram ocupadas por Eucalyptus sp. com o posterior pousio. O preparo do solo antes do plantio das leguminosas foi realizado via gradagem, posteriormente foi realizado o coveamento manual $(0,30 \mathrm{~m}$ x $0,30 \mathrm{~m}$ x $0,30 \mathrm{~m}$ ), com espaçamento $2 \times 3 \mathrm{~m}$, e fertilização, em cova, com $200 \mathrm{~g}$ de superfosfato simples. Foi realizado o semeio de cinco sementes por cova, e o ressemeio, quando necessário, foi realizado após 30 dias. Ao atingirem $20 \mathrm{~cm}$ de altura, foi realizado o raleio, deixando-se apenas uma planta por cova. Em março de 2009, com os replantios, não havia nenhuma falha na área de cultivo.

A área total da restauração é de seis hectares, sendo inicialmente plantada, em 1968, na forma de plantio puro com a espécie Paratecoma peroba (Record) Kuhlm. Em 1991 foi realizado o plantio de enriquecimento da área, com espécies nativas da Floresta Atlântica. Em 2001 foi realizado um estudo florístico na área, sendo então amostradas 43 espécies pertencentes a 23 famílias. Com diâmetro a altura do peito (DAP a $130 \mathrm{~cm}$ ) maior ou 
igual a cinco $\mathrm{cm}$, foram 22 espécies e 12 famílias e, com DAP menor do que cinco $\mathrm{cm}$, foram 27 espécies e 18 famílias. Um total de 21 espécies ocorreram somente na regeneração natural, sendo sete arbóreas e o restante de plantas que não atingem porte maior, sendo arbustivas duas espécies e herbáceas 12 espécies. Dentre as famílias presentes na área de restauração, destacam-se a Lecythidaceae, Leguminosae, Meliaceae, Sapotaceae, Myrtaceae e Bignoniaceae (Figura 1).

Para estudar a ciclagem de nutrientes, avaliou-se a serapilheira acumulada nas três áreas, em duas épocas distintas: estação chuvosa e estação seca (janeiro e julho de 2012, respectivamente). Foram coletadas, de forma aleatória no interior de cada área, 30 amostras de serapilheira acumulada com o auxílio de um gabarito com as dimensões de $0,25 \times 0,25 \mathrm{~m}$ (área útil de $0,0625 \mathrm{~m}^{2}$ ).

O material coletado foi encaminhado para o laboratório, transferido para sacos de papel devidamente identificados e seco em estufa de circulação forçada de $\operatorname{ar}\left(65^{\circ} \mathrm{C}, 72 \mathrm{~h}\right)$, para realização da pesagem, sendo que, o material mineral (solo), quando presente, foi cuidadosamente retirado. Posteriormente, o material das 30 amostras referentes a cada área em cada época de coleta, foi homogeneizado e moído, retirando-se cinco subamostras por área para análise nutricional. Foram determinados os teores de nitrogênio $(\mathrm{N})$, fósforo $(\mathrm{P})$, potássio $(\mathrm{K})$, cálcio $(\mathrm{Ca})$, magnésio $(\mathrm{Mg})$, cobre $(\mathrm{Cu})$, manganês $(\mathrm{Mn})$ e zinco $(\mathrm{Zn})$, por digestão via úmida, e o teor de boro (B) foi obtido por digestão via seca (EMBRAPA 2009; Tedesco et al. 1995).

O conteúdo de nutrientes foi estimado utilizando a equação determinada por Cuevas e Medina (1986) (Equação 1).

$$
Q N T=[\text { nutriente }] * B S D
$$

Em que: QNT $=$ Conteúdo de nutrientes $\left(\mathrm{g}^{-} \mathrm{ha}^{-}\right.$ ${ }^{1}$ ou mg ha $\left.{ }^{-1}\right)$; [nutriente] $=$ Teor do nutriente $\left(\mathrm{g} \mathrm{kg}^{-1}\right.$ ou mg kg-1); e BSD = Biomassa seca do material vegetal $\left(\mathrm{kg} \mathrm{ha}^{-1}\right)$.

Tanto para a biomassa quanto para a análise química (nutricional) da serapilheira acumulada, foi utilizado um delineamento inteiramente casualizado (DIC), em esquema fatorial, constituído de três coberturas vegetais (M. velloziana, T. cândida e Restauração) e duas épocas de coleta (estação chuvosa e estação seca). Aplicou-se o teste F a 5\% de significância e, quando se verificou diferença significativa entre as coberturas vegetais, aplicou-se o teste de médias de Tukey a 5\% de significância. As análises estatísticas foram realizadas com o auxílio do software R (R Development Core Team 2011).

\section{Resultados e discussão}

Não se verificou efeito significativo da interação entre os fatores cobertura vegetal e época de coleta, e nem da época de coleta, dentro de cada área, no que se refere aos valores médios de serapilheira acumulada. Esse fato sugeriu que a produção de serapilheira é contínua ao longo do ano, nos plantios com as espécies leguminosas e na área de Restauração. A manutenção da cobertura do solo com a camada de serapilheira é importante para se evitar a erosão deste, pelo impacto direto da gota das chuvas e pelo fornecimento de nutrientes, por meio da decomposição e mineralização da serapilheira (Tabela 1).

Entretanto, constatou-se diferenças entre os diferentes tipos de cobertura vegetal avaliados, dentro de cada estação climática. A área sob $M$. velloziana teve o maior acúmulo médio de serapilheira, na comparação com as demais áreas, em ambas as estações climáticas. O maior acúmulo de serapilheira sob o cultivo de $M$. velloziana pode estar relacionado com a forma reptante da espécie, que proporciona ampla cobertura do solo. Além disso, as folhas e ramos na parte superior de $M$. velloziana diminuem a incidência direta de radiação solar na parte inferior da planta, que entra em senescência e contribui para aumentar o acúmulo de serapilheira (Tabela 1).

Em estudo realizado por Correia et al. (2016) na mesma região, os autores observaram que quanto maior o Índice de Área de Planta (IAP), que representa a área ocupada pela parte aérea (folhas, ramos, flores e frutos) em relação à área do solo, maior é a biomassa de serapilheira acumulada sobre o solo. Os autores supracitados quantificaram a serapilheira acumulada em uma floresta em restauração há 23 anos e uma área com floresta primária adjacente, sendo encontrado os valores médios de serapilheira acumulada de 3,2 $\pm 0,94 \mathrm{Mg}$ ha- ${ }^{1}$ e 4,4 $\pm 1,39 \mathrm{Mg} \mathrm{ha}^{-1}$ nas áreas em restauração e floresta primária, respectivamente.

Por outro lado, a $T$. candida possui forma arbustiva. Com isso, grande parte da energia obtida no processo fotossintético direciona-se para o crescimento de galhos. Essas estruturas permanecem por mais tempo na planta, antes de fazerem parte da serapilheira, quando comparados às folhas, por exemplo. Esse fato pode ter contribuído para o menor acúmulo de serapilheira na área sob $T$. cândida, quando comparado à área sob $M$. velloziana. De acordo com Caldeira et al. (2014), em estudo realizado na mesma área, a biomassa acima do solo da $T$. candida era de 47,07\%, 31,27\%, $18,59 \%$ e $3,07 \%$ de galhos $>2 \mathrm{~cm}$, galhos $<2 \mathrm{~cm}$, folhas e galhos secos, respectivamente, e para a $M$. velloziana, 67,14\%, 22,94\% e 9,92\% de ramos, folhas e ramos secos, respectivamente. A biomassa total acima do solo para a $T$. candida foi de $22,14 \mathrm{Mg}$ $\mathrm{ha}^{-1}$ e para a $M$. velloziana de $15,05 \mathrm{Mg} \mathrm{ha}^{-1}$. 
Tabela 1. Valores de biomassa de serapilheira acumulada sobre o solo, seguidos do desvio padrão, em diferentes coberturas vegetais na Reserva Natural Vale, Linhares, ES.

\begin{tabular}{lcc}
\multirow{2}{*}{ Cobertura } & \multicolumn{2}{c}{ Serapilheira acumulada $\left(\mathbf{M g ~ h a}^{-\mathbf{1}}\right)$} \\
\cline { 2 - 3 } & Estação chuvosa & Estação seca \\
\hline Restauração & $8,06 \pm(2,47) \mathrm{bA}$ & $7,98 \pm(1,35) \mathrm{bA}$ \\
T. candida & $7,97 \pm(2,04) \mathrm{bA}$ & $7,36 \pm(2,25) \mathrm{bA}$ \\
M. velloziana & $12,32 \pm(1,88) \mathrm{aA}$ & $11,62 \pm(2,18) \mathrm{aA}$ \\
\hline
\end{tabular}

Valores entre parêntesis representam o desvio padrão. Médias seguidas pela mesma letra minúscula, na coluna, e pela mesma letra maiúscula, na linha, não diferem entre si pelo teste de Tukey $(p>0,05)$ ou pelo teste de $F(p>0,05)$, respectivamente.

Sabe-se que a quantidade de serapilheira acumulada sobre o solo pode variar em função da composição de espécies, idade, estádio sucessional, tipo de floresta, estação climática e características do local (Caldeira et al. 2008; Godinho et al. 2014; Siqueira et al. 2014). As espécies florestais típicas de estádios iniciais de sucessão ecológica, como as leguminosas avaliadas nesse estudo, têm alta produção de biomassa em curto espaço de tempo, refletindo assim, em grande produção e posterior acúmulo de serapilheira sobre o solo (Klippel et al. 2016; Citadini-Zanette et al. 2017). Esse elevado acúmulo de serapilheira por espécies leguminosas também foi constatado em outros estudos (Machado et al. 2012; Sperandio et al. 2012; Costa et al. 2014).

A serapilheira acumulada sob a espécie $M$. velloziana teve os maiores teores de todos os macronutrientes, nas duas épocas de coleta. A exceção coube apenas ao $\mathrm{Ca}$, cujo teor foi maior na serapilheira acumulada na Restauração, na estação seca, e não se observou diferenças entre essa área e a área sob o cultivo de $M$. velloziana, na estação chuvosa. No geral, a serapilheira acumulada na área de $T$. candida teve os menores teores de macronutrientes (Tabela 2).

A ordem decrescente de grandeza dos teores de macronutrientes para serapilheira da Restauração foi: $\mathrm{Ca}>\mathrm{N}>\mathrm{Mg}>\mathrm{K}>\mathrm{P}$ (Tabela 2), assemelhandose às sequências encontradas em outros trabalhos realizados em áreas com Floresta Atlântica ou em restauração (Caldeira et al. 2013; Godinho et al. 2014; Klippel et al. 2016). Para ambas as espécies leguminosas, a ordem decrescente de grandeza dos teores de macronutrientes foi $\mathrm{N}>\mathrm{Ca}>\mathrm{Mg}>\mathrm{K}>\mathrm{P}$. Nesse sentido, infere-se que os teores dos nutrientes estão intimamente relacionados à espécie (ou conjunto de espécies, no caso da Restauração), às condições edafoclimáticas impostas, que influenciam no metabolismo das plantas, e na mobilidade dos elementos na planta (Caldeira et al. 2010), que se refletem em aspectos da ciclagem de nutrientes.

$\mathrm{O}$ maior teor de $\mathrm{N}$ presente na serapilheira acumulada sob $M$. velloziana pode estar relacionado à capacidade de sua associação com bactérias fixadoras do N atmosférico (Cunha Neto et al. 2013; Diniz et al. 2015). Por outro lado, maiores teores relativos de $\mathrm{Ca}$, bem como de menores teores relativos de $\mathrm{P}, \mathrm{K}$ e $\mathrm{Mg}$, podem estar relacionados com a baixa ou elevada mobilidade desses nutrientes, respectivamente, dentro da planta (Marschner 1995; Caldeira et al. 2008).

Trabalhos realizados por Cunha Neto et al. (2013), Silva et al. (2013) e Citadini-Zanette et al. (2017), demonstraram que áreas revegetadas com espécies leguminosas, adicionaram sobre o solo material com maiores teores de $\mathrm{N}$, sendo importantes para a recuperação de solos degradados. Tal padrão foi observado neste estudo para $M$. velloziana.

$\mathrm{O}$ elevado teor de Ca verificado na área de Restauração foi decorrente da maior quantidade de galhos presentes na serapilheira acumulada, em comparação com as áreas sob os cultivos das espécies leguminosas. O Ca participa principalmente da constituição da parede celular, além de estar presente em grande quantidade em estruturas lignificadas e, por esse motivo, é praticamente imóvel na planta (Marschner 1995). Assim, tal macronutriente não passa por retranslocação dos tecidos mais velhos para aqueles mais jovens, e se acumula na serapilheira antes de sua queda. No processo de mineralização dos nutrientes que ocorre durante a decomposição da serapilheira, o Ca é um dos últimos macronutrientes a ser liberado para o solo (Godinho et al. 2014).

Quanto ao K, foram observadas diferenças significativas nos teores na serapilheira acumulada na comparação entre as épocas de avaliação, que foi menor na estação chuvosa (Tabela 2). O K ocorre na forma solúvel ou dissolvido no suco celular, e não participa de compostos orgânicos (Godinho et al. 2014). Desse modo, tal macronutriente tem elevada suscetibilidade à lixiviação via lavagem de folhas e de serapilheira, fato que é intensificado principalmente durante a estação chuvosa. Esse mesmo resultado foi verificado por Espig et al. (2009), que observaram uma correlação negativa significativa entre a precipitação e o teor de $\mathrm{K}$ na serapilheira, em uma Floresta Ombrófila Densa de Encosta. O P foi o macronutriente com menor teor na serapilheira acumulada sob todas as coberturas vegetais, nas duas épocas avaliadas (Tabela 2). Tal fato está relacionado ao seu baixo teor no solo 
(Caldeira et al. 2017), por vezes, condicionado pela adsorção de $\mathrm{P}$ no solo.

Quanto aos teores de micronutrientes, os maiores valores de $\mathrm{Mn}$ e $\mathrm{B}$ na serapilheira acumulada, nas duas épocas de coleta, ocorreram na Restauração, em comparação com as áreas sob as espécies leguminosas. No caso dos teores de $\mathrm{Zn}$ e $\mathrm{Cu}$, a área de Restauração continuou tendo os maiores teores em ambas as épocas de coleta, entretanto, não houve diferença com os teores da serapilheira acumulada da T. cândida (Tabela 2).

Tabela 2. Teores médios de nutrientes na serapilheira acumulada em diferentes coberturas vegetais, na Reserva Natural Vale, Linhares, ES.

\begin{tabular}{|c|c|c|c|c|c|c|c|c|c|}
\hline \multirow{3}{*}{$\begin{array}{c}\text { Cobertura } \\
\text { Vegetal }\end{array}$} & $\mathbf{N}$ & $\mathbf{P}$ & $\mathbf{K}$ & $\mathbf{C a}$ & Mg & Zn & Mn & $\mathbf{C u}$ & B \\
\hline & \multicolumn{5}{|c|}{$\mathbf{g ~ k g}^{-1}$} & \multicolumn{4}{|c|}{$\mathrm{mg} \mathrm{kg}^{-1}$} \\
\hline & \multicolumn{9}{|c|}{ Estação chuvosa } \\
\hline Restauração & $15,6 \mathrm{~b}$ & $0,4 \quad b$ & $0,9 \mathrm{~b}$ & 17,2 & a $\quad 2,7 \quad b$ & $27,5 \mathrm{ab}$ & 231,4 a & 6,2 a & 80,5 a \\
\hline T. candida & $13,1 \quad \mathrm{c}$ & $0,4 \mathrm{~b}$ & $0,4 \mathrm{c}$ & 9,9 & b $\quad 1,0 \quad c$ & 33,5 a & $56,1 \quad b$ & 5,2 a & $38,2 \mathrm{c}$ \\
\hline \multirow[t]{2}{*}{ M. velloziana } & 20,5 a & $0,7 \mathrm{a}$ & $1,7 \mathrm{a}$ & 15,8 & a 3,8 a & $24,6 \mathrm{~b}$ & $70,5 \mathrm{~b}$ & $4,9 \mathrm{~b}$ & $54,3 \mathrm{~b}$ \\
\hline & \multicolumn{9}{|c|}{ Estação seca } \\
\hline Restauração & $15,0 \mathrm{~b}$ & $0,4 \mathrm{~b}$ & $1,6 \mathrm{~b}$ & 16,3 & a $\quad 2,2 \quad b$ & $23,0 \mathrm{ab}$ & 184,7 a & 5,5 a & 75,1 a \\
\hline T. candida & $16,0 \mathrm{~b}$ & $0,4 \mathrm{~b}$ & $0,6 \mathrm{c}$ & 10,6 & $1,1 \mathrm{c}$ & 26,1 a & $74,4 \quad b$ & $5,1 \mathrm{ab}$ & $53,6 \mathrm{~b}$ \\
\hline \multirow[t]{2}{*}{ M. velloziana } & 21,1 a & $0,7 \mathrm{a}$ & 2,6 a & 13,2 & 3,3 a & $21,2 \mathrm{~b}$ & $70,5 \mathrm{~b}$ & $4,9 \mathrm{~b}$ & $54,0 \quad \mathrm{~b}$ \\
\hline & \multicolumn{9}{|c|}{ Entre estações para a mesma cobertura } \\
\hline Restauração & ns & ns & $*$ & ns & $*$ & $*$ & ns & ns & ns \\
\hline T. candida & $*$ & ns & $*$ & ns & ns & $*$ & ns & ns & $*$ \\
\hline M. velloziana & ns & ns & $*$ & $*$ & $*$ & $*$ & ns & ns & ns \\
\hline
\end{tabular}

Médias seguidas pela mesma letra minúscula na coluna, não diferem entre si pelo teste de Tukey (p>0,05), para uma mesma estação do ano. Comparação entre médias de cada nutriente pelo teste $\mathrm{F}$, entre estações para uma mesma cobertura: *significativo $(\mathrm{p}<0,05)$; e, ns não significativo $(\mathrm{p}>0,05)$.

São vários os fatores que influenciam a concentração dos micronutrientes na solução do solo, sendo que eles estão em fluxo constante. Suas concentrações dependem da força iônica da solução, da concentração de outros íons, pH, umidade, temperatura, reações de oxirredução, adição de fertilizantes e absorção pelas plantas, dentre outros. Uma pequena mudança na concentração ou na atividade das diferentes formas dos micronutrientes na solução do solo pode causar deficiência ou toxidez para as plantas (Abreu et al. 2007). Assim, os fatores supracitados irão influenciar no teor dos micronutrientes nos tecidos vegetais $\mathrm{e}$ consequentemente na serapilheira acumulada.

A ordem de grandeza decrescente dos teores de micronutrientes foi $\mathrm{Mn}>\mathrm{B}>\mathrm{Zn}>\mathrm{Cu}$ (Tabela 2). A mesma ordem encontrada em trabalhos conduzidos em Floresta Estacional Semidecidual (Caldeira et al. 2013; Godinho et al. 2014). O Mn teve o maior teor em todas as coberturas em estudo, conforme evidenciado também por Vieira et al. (2010) e Godinho et al. (2014). O alto teor de Mn pode ocorrer em função da contaminação da serapilheira acumulada com o solo, pois o Mn é proveniente de óxidos, carbonatos, silicatos e sulfetos presentes no solo, sendo comum à sua ocorrência em associação com Fe (Dechen e Nachtigall 2006).

Com relação à comparação entre as épocas de coleta, verificou-se três padrões de resposta para determinados nutrientes encerrados na serapilheira acumulada. Em primeiro lugar, não houve diferenças significativas entre as épocas de coleta no que se refere aos teores de $\mathrm{P}, \mathrm{Mn}$ e $\mathrm{Cu}$ nas três coberturas. Esse mesmo padrão de resposta de ausência de diferenças significativas entre as épocas de coleta ocorreu para os teores de $\mathrm{N}$ e $\mathrm{B}$, na serapilheira acumulada na Restauração e sob $M$. velloziana, para Ca, nas áreas de Restauração e $T$. candida, e para $\mathrm{Mg}$, na área sob T. candida (Tabela 2).

O segundo padrão, que se refere a maiores teores de $\mathrm{Zn}$ na serapilheira acumulada na estação chuvosa, em comparação com a estação seca, ocorreu para as três coberturas vegetais. No período chuvoso, os maiores valores de temperatura e conteúdo de água no solo favorecem a mineralização da matéria orgânica e, com isso, o Zn se torna mais disponível no solo para ser absorvido pelas plantas e fazer parte da serapilheira (Malavolta 2006). Essa resposta também foi observada no que se refere aos teores de $\mathrm{Ca}$, na serapilheira acumulada na área de $M$. velloziana, e de $\mathrm{Mg}$, nas áreas sob essa mesma espécie leguminosa e sob a Restauração, cujos 
maiores valores foram verificados na estação chuvosa, em detrimento da estação seca (Tabela 2).

$\mathrm{O}$ terceiro padrão guarda relação com maiores valores de teores de nutrientes na serapilheira acumulada na estação seca, na comparação com a estação chuvosa. Tal resultado ocorreu para os teores de $\mathrm{N}$ e $\mathrm{B}$, na serapilheira acumulada sob $T$. candida (Tabela 2) e para o $\mathrm{K} \mathrm{em}$ todos os tratamentos avaliados.

O conteúdo de macronutrientes teve o mesmo padrão de resposta que foi verificado para o teor de macronutrientes (Tabela 2). Desse modo, a serapilheira acumulada sob a espécie $M$. velloziana destacou-se com os maiores valores dos conteúdos de $\mathrm{N}, \mathrm{P}, \mathrm{K}$ e $\mathrm{Mg}$, nas duas estações climáticas, na comparação com as demais áreas. No caso do $\mathrm{Ca}$, os conteúdos foram maiores na serapilheira acumulada sob M. velloziana e na área de Restauração, que não se diferenciaram, na estação chuvosa, e na área de Restauração, na estação seca, quando comparado com as áreas sob as duas leguminosas. Tal resposta pode ser explicada pela conjunção entre o maior acúmulo de serapilheira e maiores teores de praticamente todos os macronutrientes no povoamento da M. velloziana (Tabela 3).

Em contrapartida, o conteúdo de $\mathrm{Mn}, \mathrm{Cu}$ e B foi significativamente maior na serapilheira acumulada na área de Restauração, em ambas as estações climáticas, quando comparado com as áreas sob as leguminosas. As duas leguminosas estudadas, por outro lado, tiveram valores semelhantes para o conteúdo de micronutrientes, na serapilheira acumulada (Tabela 3). Apenas para o Zn, os conteúdos foram maiores na serapilheira acumulada sob $T$. candida em relação à área de $M$. velloziana (nas duas estações climáticas), sendo que não houve diferenças significativas entre essas áreas e a área de Restauração (Tabela 3).

O conteúdo médio total de macronutrientes na serapilheira acumulada foi de 339,8, 294,0 e $198,3 \mathrm{~kg} \mathrm{ha}^{-1}$ na estação chuvosa, e de 326,0, 283,5 e $229,2 \mathrm{~kg} \mathrm{ha}^{-1}$ na estação seca, para M. velloziana, Restauração e $T$. candida, respectivamente (Tabela 3). A ordem decrescente dos conteúdos foi: $\mathrm{Ca}>\mathrm{N}$ $>\mathrm{Mg}>\mathrm{K}>\mathrm{P}$ para a Restauração, e $\mathrm{N}>\mathrm{Ca}>\mathrm{Mg}>$ $\mathrm{K}>\mathrm{P}$ para as leguminosas. Os conteúdos de macronutrientes encontrados neste estudo para a área de Restauração são inferiores aqueles observados por Diniz et al. (2015) em área de Floresta Estacional Semidecidual, Pinheiral, RJ, principalmente pela elevada biomassa de serapilheira acumulada encontrada no fragmento florestal estudado pelos autores $\left(17,5 \mathrm{Mg} \mathrm{ha}^{-1}\right)$. Contudo, os valores são próximos aos conteúdos verificados por Godinho et al. (2014) em Floresta Estacional Semidecidual em Cachoeiro do Itapemirim, ES e aos de Klippel et al. (2016) em áreas em restauração florestal também na Reserva Natural Vale, em Linhares, ES.

O plantio de espécies florestais e, ou, de cobertura provoca mudanças nas condições ambientais (efeito catalítico), as quais se tornam mais adequadas, o que favorece a germinação e crescimento das espécies vegetais (Parrotta et al. 1997). As leguminosas são espécies vegetais comumente utilizadas para melhorar a qualidade de solos em projetos de recuperação de áreas degradadas, uma vez que contribuem com grande aporte de serapilheira e com a fixação biológica de N (Klippel et al. 2016). Segundo Nguyen e Shindo (2011), em ecossistemas florestais, nos quais o ciclo de crescimento é mais longo, o $\mathrm{N}$ orgânico é a principal fonte de $\mathrm{N}$ para as plantas, pois cerca de $95 \%$ do $\mathrm{N}$ total do solo se encontra na matéria orgânica.

Essa melhoria das condições ecológicas, realizada pelas espécies florestais e, ou, plantas de cobertura, pode ser em termos de recuperação da ciclagem de nutrientes e da fertilidade em solos degradados, fornecimento de sombra, inibição da matocompetição, dentre outros. Por isso, a maioria dos projetos de recuperação de áreas degradadas busca estimular a sucessão via facilitação, por exemplo, por meio do plantio de espécies leguminosas fixadoras de nitrogênio (Silva et al., 2007; Martins, 2009). Nesse ponto, os Sistemas Agroflorestais (SAFs) podem ocupar papel de destaque, desde que a escolha das espécies, primeiro passo para o manejo bem-sucedido do SAF, seja adequada (Silva et al., 2007).

A seleção das espécies que irão compor um projeto de recuperação de áreas degradadas e, ou, restauração é uma etapa de suma importância para o seu sucesso. Portanto, no geral, a espécie $M$. velloziana seria recomendada para o plantio inicial em áreas degradadas, uma vez que a serapilheira acumulada nesse tipo de cobertura vegetal retornou não só o maior conteúdo de $\mathrm{N}$ para o solo, como também de $\mathrm{P}, \mathrm{K}$ e $\mathrm{Ca}$, de uma maneira geral. Ademais, Silva et al (2007), relata que é importante buscar a sincronia entre o período de maior disponibilidade de nutrientes no sistema, normalmente proveniente de práticas como a poda, com a demanda da cultura de interesse. Assim, podese plantar inicialmente a $M$. velloziana em áreas degradadas para que ela melhore as condições ambientais, sendo incorporada posteriormente no solo, antecedendo o plantio das espécies de interesse, por exemplo, as de diversidade.

As plantas de cobertura também podem ser plantadas concomitantemente com as espécies perenes, sendo que a duração do ciclo das plantas de cobertura vai depender do tempo disponível ("janela" de rotação) para serem cultivadas. Em geral, não deve ser menor do que 60 dias e nem superior a 90 dias, para não comprometer a rentabilidade econômica da propriedade. Nessa modalidade, a planta de cobertura ocupa toda a área durante o tempo reservado para o estabelecimento de seus efeitos. Assim, as plantas produzem as maiores 
quantidades de biomassa e promovem um forte abafamento do mato (Angeletti et al., 2018).

Tabela 3. Conteúdo médio de nutrientes na serapilheira acumulada em diferentes coberturas vegetais, na Reserva Natural Vale, Linhares, ES.

\begin{tabular}{|c|c|c|c|c|c|c|c|c|c|c|c|c|}
\hline \multirow{3}{*}{ Cobertura Vegetal } & $\mathbf{N}$ & & $\mathbf{P}$ & $\mathbf{K}$ & & $\mathbf{C a}$ & Mg & & $\mathbf{Z n}$ & Mn & $\mathbf{C u}$ & B \\
\hline & \multicolumn{12}{|c|}{$\mathrm{kg} \mathrm{ha}^{-1}$} \\
\hline & \multicolumn{12}{|c|}{ Estação chuvosa } \\
\hline Restauração & 124,4 & $\mathrm{~b}$ & $3,3 \mathrm{~b}$ & 6,8 & $\mathrm{~b}$ & 137,6 a & 21,9 & $\mathrm{~b}$ & $0,22 \mathrm{ab}$ & 1,85 a & 0,05 a & 0,67 a \\
\hline T. candida & 104,6 & $\mathrm{c}$ & $3,3 \mathrm{~b}$ & 3,2 & $\mathrm{c}$ & $79,3 \mathrm{~b}$ & 7,9 & $\mathrm{c}$ & 0,27 a & $0,45 \mathrm{~b}$ & $0,04 \mathrm{~b}$ & $0,31 \mathrm{c}$ \\
\hline \multirow[t]{2}{*}{ M. velloziana } & 163,8 & $\mathrm{a}$ & 5,7 a & 13,7 & $\mathrm{a}$ & $126,2 \mathrm{a}$ & 30,4 & $\mathrm{a}$ & $0,19 \mathrm{~b}$ & $0,56 \mathrm{~b}$ & $0,04 \mathrm{~b}$ & $0,43 \mathrm{~b}$ \\
\hline & \multicolumn{12}{|c|}{ Estação seca } \\
\hline Restauração & 119,7 & $\mathrm{~b}$ & $3,4 \mathrm{~b}$ & 12,7 & $\mathrm{~b}$ & 130,2 a & 17,5 & & $0,18 \mathrm{ab}$ & 1,48 a & 0,05 a & $0,60 \mathrm{a}$ \\
\hline T. candida & 128,0 & $\mathrm{~b}$ & $3,3 \mathrm{~b}$ & 4,7 & $\mathrm{c}$ & 84,3 c & 8,9 & $\mathrm{c}$ & 0,21 a & $0,59 \mathrm{~b}$ & $0,04 \mathrm{~b}$ & $0,43 \mathrm{~b}$ \\
\hline \multirow[t]{2}{*}{ M. velloziana } & 168,9 & $\mathrm{a}$ & 5,4 a & 20,4 & $\mathrm{a}$ & $105,1 \mathrm{~b}$ & 26,2 & a & $0,17 \mathrm{~b}$ & $0,56 \mathrm{~b}$ & $0,04 \mathrm{~b}$ & $0,43 \mathrm{~b}$ \\
\hline & \multicolumn{12}{|c|}{ Entre estações para cada cobertura } \\
\hline Restauração & ns & & ns & $*$ & & ns & $*$ & & $*$ & ns & ns & ns \\
\hline T. candida & $*$ & & ns & $*$ & & $\mathrm{~ns}$ & ns & & $*$ & ns & ns & $*$ \\
\hline M. velloziana & ns & & ns & $*$ & & $*$ & $*$ & & $*$ & ns & ns & $\mathrm{ns}$ \\
\hline
\end{tabular}

Médias seguidas pela mesma letra minúscula na coluna, não diferem entre si pelo teste de Tukey $(\mathrm{p}>0,05)$, para uma mesma estação do ano. Comparação entre médias de cada nutriente pelo teste $\mathrm{F}$, entre estações para uma mesma cobertura: *significativo $(\mathrm{p}<0,05)$; e, ns não significativo $(\mathrm{p}>0,05)$.

\section{Conclusões}

A leguminosa $M$. velloziana proporciona o maior acúmulo de serapilheira no solo, assim como maiores teores e conteúdo de praticamente todos os macronutrientes, entre as coberturas vegetais avaliadas, em ambas as estações climáticas. Portanto, essa espécie seria mais indicada do que a T. candida para ser utilizada na recuperação de áreas degradadas.

Os maiores teores e conteúdo da maioria dos micronutrientes analisados são verificados na serapilheira acumulada sobre o solo na área de Restauração.

\section{Agradecimentos}

À Reserva Natural Vale, pela hospedagem, disponibilidade da área do estudo e apoio nos trabalhos de campo.

\section{Referências bibliográficas}

Abreu CA de, Lopes AS, Santos GCG dos (2007) Micronutrientes. In: Novais RF, Alvarez VH, Fontes RLF, Cantarutti RB, Neves JCL (ed) Fertilidade do Solo: Viçosa: Sociedade Brasileira de Ciência do Solo. p.645-736.

Alvares CA, Stape JL, Sentelhas PC, Gonçalves JL de M, Sparovek G (2013) Köppen's climate classification map for Brazil. Meteorologische
Zeitschrift, 22(6):711-728. doi: 10.1127/09412948/2013/0507.

Angeletti M da P, Souza JL de, Costa H, Favarato LF, Muzzi E de M, Muniz ES, Laurett L, Zanuncio Junior JS, Martins AG (2018) Espécies vegetais para cobertura de solo: guia ilustrado. Vitória: Incaper. $76 \mathrm{p}$.

Caldeira MVW, Godinho $\mathrm{T}$ de $\mathrm{O}$, Moreira FL, Campanharo ÍF, Castro KC, Mendonça AR de, Trazzi PA (2019) Litter as an Ecological Indicator of Forest Restoration Processes in a Dense Ombrophylous Lowland Forest. Floresta $e$ Ambiente, 26(spe1):e20180411. doi: 10.1590/21798087.041118 .

Caldeira MVW, Moreira FL, Gonçalves E de O, Campanharo IF, Castro KC (2017) Teor e redistribuição de nutrientes nas folhas de Bixa arborea Huber. e Joannesia princeps Vell. em área de restauração florestal. Scientia Forestalis, 45(114):305-317. doi: 10.18671/scifor.v45n114.07.

Caldeira MVW, Silva RD, Kunz SH, Zorzanelli JPF, Castro KC, Godinho T de O (2013) Biomassa e nutrientes da serapilheira em diferentes coberturas florestais. Comunicata Scientiae, 4(2):111-119. 
Caldeira MVW, Sperandio HV, Delarmelina WM, Burak DL, Hunz SH (2014) Biomassa e nutrientes em diferentes compartimentos acima do solo das espécies Mimosa velloziana Mart. e Tephrosia candida D.C. Ecologia e Nutrição Florestal, 2(1):918. doi: 10.5902/2316980X15225.

Caldeira MVW, Vitorino MD, Schaadt SS, Moraes E, Balbinot R (2008) Quantificação de serapilheira e de nutrientes em uma Floresta Ombrófila Densa. Semina: Ciências Agrárias, 29(1):53-68. doi: 10.5433/1679-0359.2008v29n1p53.

Caldeira WVW, Schumacher MV, Viera M, Gonçalves EO, Godinho T de O (2010) Ciclagem de nutrientes, via deposição e acúmulo de serapilheira, em ecossistemas florestais. In: Chichorro JF, Garcia GO, Caldeira MVW, Bauer MO (ed) Tópicos em Ciências Florestais. Alegre: Suprema. p.57-82.

Chaer GM, Resende AS, Campello EFC, Faria SM de, Boddey RM (2011) Nitrogen-fixing legume tree species for the reclamation of severely degraded lands in Brazil. Tree Physiology, 31(2):139-149. doi: 10.1093/treephys/tpq116.

Citadini-Zanette V, Negrelle RRB, Leal-Filho LS, Remor R, Elias GA, Santos R (2017) Mimosa scabrella Benth. (Fabaceae) enhances the restoration in coal mining areas in the Atlantic Rainforest. Cerne, 23(1):103-114. doi: 10.1590/01047760201723012245.

Correia GG de S, Martins SV, Miranda Neto A, Silva $\mathrm{K}$ de A (2016) Estoque de serapilheira em floresta em restauração e em Floresta Atlântica de Tabuleiro no Sudeste Brasileiro. Revista Árvore, 40(1):13-20. doi. 10.1590/0100-67622016000100002.

Costa MG da, Gama-Rodrigues AC da, Zaia FC, Gama-Rodrigues EF da (2014) Leguminosas arbóreas para recuperação de áreas degradadas com pastagem em Conceição de Macabu, Rio de Janeiro, Brasil. Scientia Forestalis, 42(101):101-112.

Cuevas E, Medina E (1986) Nutrient dynamics within amazonian forest ecosystems. Oecologia, (68):446-472. doi: 10.1007/BF01036756.

Cunha Neto FV, Leles PSS, Pereira MG, Bellumath VGH, Alonso JM (2013) Acúmulo e decomposição da serapilheira em quatro formações florestais. Ciência Florestal, 23(3):379-387. doi: 10.5902/1980509810549.

Dechen AR, Nachtigall GR (2006) Micronutrientes. In: Fernandes, M. S. (ed) Nutrição Mineral de Plantas. Viçosa: Sociedade Brasileira de Ciência do Solo (SBCS). p.327-354.
Diniz AR, Machado DL, Pereira MG, Balieiro F de C, Menezes CEG (2015) Biomassa, estoques de carbono e de nutrientes em estádios sucessionais da Floresta Atlântica, RJ. Agrária - Revista Brasileira de Ciências Agrárias, 10(3):443-451. doi: 10.5039/agraria.v10i3a4264.

EMBRAPA - Empresa Brasileira de Pesquisa Agropecuária (2006) Sistema brasileiro de classificação de solos. 2 ed. Rio de Janeiro: EMBRAPA. 306p.

EMBRAPA - Empresa Brasileira de Pesquisa Agropecuária (2009) Manual de análises químicas de solos, plantas e fertilizantes. 2 ed. Brasília: Embrapa informação Tecnológica. 627p.

Espig AS, Freire FJ, Marangon LC, Ferreira RLC, Freire MBG dos S, Espig DB (2009) Sazonalidade, composição e aporte de nutrientes da serapilheira em fragmento de mata atlântica. Revista Árvore, 33(5):949-956. doi: 10.1590/S010067622009000500017.

Freitas ECS de, Oliveira Neto SN de, Fonseca DM da, Santos MV, Leite HG, Machado VD (2013) Deposição de serapilheira e de nutrientes no solo em sistema agrossilvipastoril com eucalipto e acácia. Revista Árvore, 37(3):409-417. doi: 10.1590/S010067622013000300004.

Godinho T de O, Caldeira MVW, Caliman JP, Prezotti LC, Watzlawick LF, Azevedo HCA, Rocha JHT (2013) Biomassa, macronutrientes e carbono orgânico na serapilheira depositada em trecho de floresta Estacional Semidecidual Submontana, ES. Scientia Forestalis, 41(97), p. 131-144.

Godinho T de O, Caldeira MVW, Rocha JHT, Caliman JP, Trazzi PA (2014) Quantificação de biomassa e de nutrientes na serapilheira acumulada em trecho de floresta estacional semidecidual submontana, ES. Cerne, 20(1):11-20. doi: 10.1590/S0104-77602014000100002.

Gomes Júnior D, Caldeira MVW, Klippel VH, Mendonça E de S, Delarmelina WM, Godinho T de O, Rocha RLF (2019) Decomposition of Leaf Litter in Semideciduous Submontane Forest, in The Southern State of Espírito Santo. Floresta $e$ Ambiente, 26(spe1)e20180400. doi: 10.1590/21798087.040018 .

Klippel VH, Pezzopane JEM, Caldeira MVW, Silva GF da, Castro KC (2016) Acúmulo de serapilheira e nutrientes em área com diferentes metodologias de Restauração Florestal. Comunicata Scientiae, 7(2): 241-250. doi: 10.14295/CS.v7i2.521. 
Klippel VH, Pezzopane JEM, Silva GF da, Caldeira MVW, Pimenta LR, Toledo JV (2015) Avaliação de métodos de restauração florestal de Mata de Tabuleiros-ES. Revista Árvore, 39(1):69-79. doi: 10.1590/0100-67622015000100007.

Longo RM, Ribeiro AI, Melo WJ de (2011) Recuperação de solos degradados na exploração mineral de cassiterita: biomassa microbiana $\mathrm{e}$ atividade da desidrogenase. Bragantia, 70(1):132138. doi: 10.1590/S0006-87052011000100019.

Machado FA, Bezerra Neto E, Nascimento M do PSCB, Silva LM, Barreto LP, Nascimento HTS, Leal JA (2012) Produção e qualidade da serrapilheira de três leguminosas arbóreas nativas do nordeste do Brasil. Archivos de Zootecnia, 6(235):323-334. doi: 10.4321/S000405922012000300001 .

Malavolta E. (2006) Manual de nutrição mineral de plantas. São Paulo: Agronômica Ceres. 638p.

Marschner, H. (1995) Mineral nutrition of higher plants. 2. ed. San Diego: Academic. 889p.

Martins SV (2009) Recuperação de áreas degradadas: ações em áreas de preservação permanente, voçorocas, taludes rodoviárias e de mineração. Viçosa: Aprenda Fácil. 270 p.

Myers N, Mittermeier RA, Mittermeier, CG, Fonseca GAB da, Kent J (2000) Biodiversity hotspots for conservation priorities. Nature, 403:852-858. doi: 10.1038/35002501.

Nascimento LS, Cerqueira RM, Henderson BLR (2015) Produção de serapilheira em um fragmento adjacente a uma cava de mineração, Ribeirão Grande, SP. Revista Brasileira de Engenharia Agrícola e Ambiental, 19(9):892-897. doi: 10.1590/1807-1929/agriambi.v19n9p892-897.

Nguyen TH, Shindo H (2011) Effects of different levels of compost application on amounts and distribution of organic nitrogen forms in soil particle size fractions subjected mainly to double cropping. Agricultural Sciences, 2(3):213-219. doi: 10.4236/as.2011.23030.

Parrotta JA, Turnbull JW, Jones N (1997) Catalyzing native forest regeneration on degraded tropical lands. Forest Ecology and Management, 99(1-2):17.

Piña-Rodrigues FCM, Reis LL, Marques SS (1997) Sistema de plantio adensado para a revegetação de áreas degradas da Mata Atlântica: bases ecológicas e comparações custo-benefício com o sistema tradicional. Floresta e Ambiente, 4:30-41.
R Development Core Team (2011) PC-ORD R: A language and environment for statistical computing. Vienna, Austria.

Ribeiro MC, Metzger JP, Martensen AC, Ponzoni FJ, Hirota MM (2009) The brazilian Atlantic Forest: how much is left, and how in the remaining forest distributed? Implications for conservation. Biological Conservation, 142(6):1141-1153. doi: 10.1016/j.biocon.2009.02.021.

Saiter FZ, Rolim SG, Jordy Filho S, Oliveira-Filho AT de (2017) Uma revisão sobre a controversa classificação fisionômica da Floresta de Linhares, norte do Espírito Santo. Rodriguésia, 68(5):19871999. doi: 10.1590/2175-7860201768529.

Silva AB, Lira Junior MA, Dubeux Junior JCB, Figueiredo M do VB, Vicentin RP (2013) Estoque de serapilheira e fertilidade do solo em pastagem degradada de Brachiaria decumbens após implantação de leguminosas arbustivas e arbóreas forrageiras. Revista Brasileira de Ciência do Solo, 37(2):502-511. doi: 10.1590/S010006832013000200021 .

Silva GTA, Resende AS de, Campello EFC, Dias PF, Franco AA (2007) O papel da fixação biológica de nitrogênio na sustentabilidade de sistemas agroflorestais. Seropédica: Embrapa Agrobiologia. $36 \mathrm{p}$.

Siqueira PL de OF, Silva PSL e, Silva KEF, Oliveira VR de, Dantas IM, Oliveira FHT de (2014) Soil fertility beneath the crown of tree species submitted to planting densities. Revista Brasileira de Engenharia Agrícola e Ambiental, 18(9):914-919. doi: 10.1590/1807-1929/agriambi.v18n09p914-919.

SOS MATA ATLÂNTICA (2016) Relatório Anual 2016. São Paulo: Fundação SOS Mata Atlântica. 104 p.

Sperandio HV, Cecilio RA, Silva VH, Leal GF, Brinate IB, Caldeira MVW (2012) Emprego da serapilheira acumulada na avaliação de sistemas de restauração florestal em Alegre, ES. Floresta $e$ Ambiente, 19(4):460-467. doi: doi.org/10.4322/floram.2012.060.

Tedesco MJ, Gianello C, Bissani CA, Bohnen H, Volkweiss SJ (1995) Análise de solo, plantas e outros materiais. 2 ed. Porto Alegre: Departamento de Solos, UFRGS. 118p.

Vieira M, Caldato SL, Rosa SF da, Kanieski MR, Araldi DB, Santos SR dos, Schumacher MV (2010) Nutrientes na serapilheira em um fragmento de Floresta Estacional Decidual, Itaara, RS. Ciência 
Caldeira et al.

Florestal, 20(4):611-619. doi: $10.5902 / 198050982419$. 